\title{
ONCOLOGIA OCULAR
}

\author{
OCULAR TUMORS
}

Laudo Silva Costa

Docente do Departamento de Oftalmologia e Otorrinolaringologia da Faculdade de Medicina de Ribeirão Preto da Universidade de São Paulo.

CorRESPONDÊNCIA: Departamento de Oftalmologia e Otorrinolaringologia da Faculdade de Medicina de Ribeirão Preto - Campus Universitário - CEP: 14048-900 - Ribeirão Preto - SP - Fax: (016) 633-0186.

COSTA LS. Oncologia ocular. Medicina, Ribeirão Preto, 30: 74-75, jan./mar. 1997.

RESUMO: O carcinoma da conjuntiva, o melanoma de coróide e o retinoblastoma são neoplasias familiares ao oftalmologista.

O primeiro é de fácil detecção e tratamento. Em compensação, o segundo é de um diagnóstico mais difícil, e o seu tratamento tem sido um enervante quebra-cabeça para os especialistas, permanecendo controverso até os dias de hoje. O retinoblastoma é encontrado na criança, trazendo a possibilidade de acometimento bilateral. É uniformemente maligno, e o seu tratamento, que se centraliza na Radioterapia, depende de um estadiamento criterioso.

UNITERMOS: Carcinoma. Conjuntiva. Coróide. Melanoma. Neoplasias Oculares. Retinoblastoma.

Os três tumores oculares, encontrados com mais freqüência na clínica oftalmológica convencional são: o carcinoma de conjuntiva, o melanoma de coróide e o retinoblastoma.

O carcinoma espinocelular é um tumor comum na conjuntiva bulbar. Ele aparece mais freqüentemente no limbo (região de transição entre a esclera e a córnea). Raramente acontece de aparecer na conjuntiva palpebral ou, isoladamente, no epitélio corneano. $\mathrm{O}$ aspecto deste tumor é, freqüentemente, o de uma placa, ou um nódulo que surge, portanto, na transição esclerocorneal, sempre na área que as pálpebras não cobrem, e que, em razão disto, pode ser rápida e facilmente notado pela pessoa afetada, quando ela está cuidando de sua higiene matinal. Alguns autores comentam que, se alguém está destinado a padecer de um carcinoma, então, estará com sorte se tratar-se de um carcinoma conjuntival, porque o tumor será notado em uma fase em que, certamente, deixaria de ser percebido, se surgisse em um epitélio diferente, como a vesícula urinária, o estômago, o esôfago ou outro. Talvez por este aparecimento precoce e pela sua índole geralmente pouco agressiva, este tumor comporta um tratamento eficaz. De fato, o crescimento e a invasão neoplásica são lentos, salvo na variedade mucoepidermóide. Esta última é perigosa. Mas, em geral, a abordagem cirúrgica é tranquiila, sendo que o comprometimento metastático é raro. A recidiva pode ocorrer, e, na realidade, é freqüente, mas comporta nova ressecção. O tratamento de escolha é a excisão completa do tumor, sendo o limbo o local em que a margem de corte precisa ser aumentada. O tratamento crioterápico da ferida cirúrgica ajuda a dificultar a recidiva.

O melanoma de coróide não compartilha com o tumor anterior nenhuma daquelas características. Ele cursa com uma fase inicial de tempo prolongado e assintomática. E, quando diagnosticado, é bem possível que já tenha suas células circulando na corrente sangüínea, e sendo detidas no fígado. O diagnóstico é feito pelo exame de fundo de olho, em geral, quando o paciente atinge a segunda fase da história natural deste tumor, ou seja, a fase de sintomas visuais. Isto porque o tumor provoca uma mancha no campo visual, onde ele descola e desorganiza a retina. $\mathrm{O}$ exame de fundo de olho mostra, freqüentemente, uma massa pigmentada associada a áreas de descolamento retiniano. $\mathrm{O}$ 
exame ecográfico da massa intra-ocular costuma mostrar um padrão ecóico fácil de reconhecer, e o diagnóstico diferencial deve ser feito com o nevo de coróide, o hemangioma ou com os tumores metastáticos (sendo estes, em geral, originários da mama, tubo digestório ou pulmão). $O$ tratamento deste tumor é controverso. Desde a década de 70 o tratamento tem sido campo de calorosas discussões, porque apareceram trabalhos clínicos mostrando que a sobrevida dos pacientes que recusavam a enucleação do globo ocular era a mesma sobrevida daqueles que se submetiam à cirurgia. Também surgiram publicações, relacionando a intervenção cirúrgica com o aumento da constatação de metástases à distância, possivelmente resultantes da manipulação do globo ocular durante o procedimento de enucleação. O tumor não responde a radioterapia nem a quimioterapia antineoplásica, restringindo a discussão do tratamento, principalmente, ao ato cirúrgico. $\mathrm{O}$ ato cirúrgico, que consiste em enuclear o globo ocular portador de um melanoma cujo diâmetro está acima de $13 \mathrm{~mm}$, é considerado, por alguns autores, como sendo desvantajoso. Outros consideram-no adequado. $\mathrm{O}$ prognóstico apresenta uma mortalidade de até $50 \%$, no prazo de 5 anos. O aparecimento de metástases é uniformemente letal.

Enquanto os dois tumores anteriores são adquiridos, o retinoblastoma é um tumor congênito. Trata-se de neoplasia altamente maligna, que surge na retina de globo ocular bem formado (a presença de malformação afasta o retinoblastoma). Sua incidência vem subindo, sem que seja possível esclarecer o motivo. O acometimento é bilateral em cerca de $20 \%$ dos casos, e uma tendência hereditária pode ser registrada em cerca de $40 \%$. O tumor é notado pelo brilho cinza-claro, que surge na pupila (leucocoria). Isto ocorre em $60 \%$ dos casos. Em $20 \%$ dos casos, o tumor provoca um estrabismo, o que torna o aparecimento de estrabismo súbito, em crianças, um problema de pronto-socorro. Pode também aparecer sob a forma de baixa visão, massa orbitária, inflamação ocular, midríase, hifema, inflamação orbitária. Podemos considerar este tumor em 4 estádios: inicialmente ele atinge somente a retina, lugar de sua origem. Em segundo lugar, invade estruturas intra-oculares. Em terceiro lugar, o tumor ganha o exterior do globo ocular, mantendo-se em suas cercanias. Finalmente, ele solta metástases à distância, por via linfática e sangüínea. O diagnóstico é feito pelo exame de fundo de olho e pela ecografia oftálmica, a qual fornece um padrão facilmente reconhecível. Ocasionalmente, a tomografia pode contribuir. Diferencia-se a neoplasia dos seguintes processos: inflamação intra-ocular provocada pela Toxocara canis, doença de Coats, persistência de vítreo primário hiperplásico, fibroplasia retrolental, displasia da retina, coloboma da retina. $\mathrm{O}$ tratamento do retinoblastoma tem bom resultado com radioterapia, à qual ele é muito sensível. A enucleação do globo ocular tomado por grande massa tumoral é aconselhável, devendo o procedimento ser pouco manipulativo e a secção do nervo óptico efetuar-se tanto posteriormente quanto possível. De maneira complementar, utilizamos a crioterapia, a fotocoagulação e a quimioterapia. O prognóstico é bem melhor do que o do melanoma de coróide, e pior do que o do carcinoma de conjuntiva.

COSTA LS. Ocular tumors. Medicina, Ribeirão Preto, 30: 74-75, jan./march 1997.

ABSTRACT: Epithelioma of the conjunctiva, malignant melanoma of the choroid and retinoblastoma are not infrequent. Diagnosis and treatment of the former tumor is an easy task. But melanoma demands extreme care in diagnosis and treatment is frequently of an unpleasant nature. Retinoblastoma is a tumor of childhood and the condition is becoming more common. A bilateral incidence may occur and the further course of the tumor is of progressive spread. Established treatment for retinoblastoma is radiation.

UNITERMS: Carcinoma. Conjunctiva. Choroid. Melanoma. Eye Neoplasms. Retinoblastoma.

\section{BIBLIOGRAFIA RECOMENDADA}

1 - CRAWFORD JB. Conjunctival tumors. In: TASMAN W \& JAEGER EA. Duane's Clinical ophthalmology. Lippincott; Raven Press, Philadelphia, New York, v. 4, Cap. 10, p. 1-10, 1995.

2 - SHIELDS JA. Tumors of the uveal tract. In: TASMAN W \& JAEGER EA. Duane's Clinical ophthalmology. Lippincott; Raven Press, Philadelphia, New York, v. 4, cap. 68, p. 1-15, 1995.
3 - ELLSWORTHRM \& BOXRUD CA. Retinoblastoma. In: TASMAN $W$ \& JAEGER EA. Duane's Clinical ophthalmology. Lippincott; Raven Press, Philadelphia, New York, v. 3, cap. 35, p. 1-19, 1995.

Recebido para publicação em 03/01/97

Aprovado para publicação em 30/01/97 